Article

\title{
Introduction of Building Information Modeling in Industrial Engineering Education: Students' Perception
}

\author{
Alberto Sánchez ${ }^{1, *}$, Cristina Gonzalez-Gaya ${ }^{2} \oplus$, Patricia Zulueta ${ }^{1}$ and Zita Sampaio ${ }^{3}$ \\ 1 Department of Materials Science and Metallurgical Engineering, Graphic Expression in Engineering, \\ Cartographic Engineering, Geodesy and Photogrammetry, Mechanical Engineering and Manufacturing \\ Engineering, Universidad de Valladolid, Paseo del Cauce, 59, 47011 Valladolid, Spain \\ 2 Department of Construction and Manufacturing Engineering, ETSII-Universidad Nacional de Educación a \\ Distancia (UNED), C/Juan del Rosal 12, 28040 Madrid, Spain \\ 3 Department of Civil Engineering, Architecture and Georesources, Instituto Superior Técnico, Universidade \\ de Lisboa, Avenida Rovisco Pais, 1049-001 Lisboa, Portugal \\ * Correspondence: asanchez@eii.uva.es
}

Received: 21 July 2019; Accepted: 8 August 2019; Published: 11 August 2019

check for updates

Featured Application: This approach allows the assessment of building information modeling (BIM) implementation in the formal teaching system, taking into account the student perceptions of BIM in the engineering project course.

\begin{abstract}
The building information modeling (BIM) methodology is becoming a mandatory requirement in the development of projects within the world context. Consequently, technical schools have been introducing BIM in their curricula. The present study aims to evaluate student perceptions concerning the advantages and difficulties of incorporating BIM into the formal teaching system as part of the degree in industrial engineering. Students' understanding and satisfaction were analyzed while using BIM in the development of the practical component of a didactic industrial project. The evaluation was based on a Likert survey with five levels, and the results were interpreted using a factor analysis and ascending hierarchical classification. To identify possible relationships between student satisfaction with the BIM implementation and the factors obtained, a multiple regression analysis was performed. It was determined that students have a high perception of BIM utility and consider the use of the BIM tool that is intuitive and easy to learn, including during the autonomous learning process. The results show a direct correlation between the benefits of BIM implementation in industrial projects and the advantages of defining teamwork within collaborative projects. The incorporation of BIM as a mandatory subject in the industrial engineering curriculum appears to be successful, and the results are encouraging.
\end{abstract}

Keywords: BIM; engineering standards; collaborative learning; multidisciplinary design; industrial engineering; project engineering

\section{Introduction}

The USA organizations of the National Building Information Modeling Standards (NBIMS) and the Associated General Contractors of America (AGC) define "Building Information Modeling (BIM) as a technology and a process: the technology component helps to visualize what is to be built in a simulated environment and the process aspect enables close collaboration and encourages integration of the roles of all stakeholders on a project" [1]. BIM allows a better understanding of project modeling and implementation from a global perspective, involving all industrial engineering 
teams and creating an opportunity in which each specialist can provide great value. The transition from drafting 2D projects to a BIM platform is not just a technical update. The BIM teaching experience in construction engineering and management suggests the need to focus on BIM learning as an improved methodology $[2,3]$.

BIM is a collaborative work methodology. The work methodology is based on a central 3D model that contains all engineering project data. According to the diagram of Mark Bew and Mervyn Richards, four levels of BIM maturity are distinguished (0-3 levels): Level 0: Two-dimensional (2D) model; information is primarily paper-based; no collaborative work. Level 1: Three-dimensional (3D) model; digital information; poor collaborative work. Level 2: Starter level of BIM; 3D model; digital information; model without a completed database; more collaborative work. Level 3: 3D model (a single model); digital information; model with a completed, fully integrated database; fully collaborative work $[4,5]$.

The construction industry has experimented with rapidly changing technology and supported constant advances, refinements or improvements from a wide range of work or platform methodologies for collaborative projects that are mainly reinforced by the BIM methodology. To remain competitive in business, companies are urged to try professional approaches that demand brand new knowledge and skillsets, namely, BIM. There is an interest in learning the BIM methodology and a range of applications in all paths that lead to industrial and manufacturing sectors. As Bozoglu notes, knowledge of BIM should begin at the academy [6]. Schools have a commitment to education, and recently, BIM has been introduced in technical curricular programs. The implementation of BIM has become a dynamic aspect of university education and subsequent professional development.

The academic reality confirms a substantial improvement in the adoption and application of BIM in educational settings. However, the professional community advances more rapidly than the academic community. Currently, a gap has been confirmed between the rapid growth of the labor market in relation to BIM and the incentives needed to encourage teachers to update their skills with BIM and transmit them to students. One of the primary issues in incorporating BIM into engineering education is to make educators aware of various BIM utilization aspects and encourage them to find possible solutions for optimizing BIM use in their existing courses. Additionally, contact with the industry is mandatory for this purpose. However, there are still various major barriers to the implementation of BIM in educational settings, and the traditional way of teaching is one of them. Consequently, a broader and more proactive association involving all the relevant areas could be the solution for advancing BIM education and talent acquisition in architecture, engineering, and the construction industry [7-10].

However, the present lack of skilled BIM educators calls for educating the educators and thus acquainting them with the BIM processes, concepts and technologies. The capability of higher education to keep up with the changing expectations of competency from industry partners imposes the aforementioned rapid development within formal academia as well as educational solutions from outside the education system.

Different reports focused to a greater or lesser extent on industry needs show a growing interest in BIM implementation in university education [7-15]. Currently, there is a clear interest in BIM implementation in Europe that has been motivated by the implementation of directives established by the Council of the European Union and European Parliament (Directive 2014/24/EU).

From the results of Adamu and Thorpe's study [16], it can be deduced that BIM training requires long-term vision, leadership, and cooperation in the academic environment. In their study, they employed a feedback mechanism to capture student experiences with respect to their BIMLOs, access to facilities, and the effectiveness of guided autonomous learning through internet video tutorials, and they advised other institutions to consider this approach to achieve multidisciplinary integration of BIM in their curriculum. In Spain, different universities are developing implementation systems in their curricula for degrees in construction engineering and architecture [17-20] and in industrial engineering [21-24]. Forty-seven percent of engineering schools are currently incorporating 
BIM training programs into their undergraduate and postgraduate degrees, representing $12 \%$ of all training programs in architecture, civil engineering, industrial engineering, and building/technical architecture [25].

Mainly at the Polytechnic University of Madrid, the school of architecture offers a specialization course in continuing education concerning the BIM methodology that is part of a master's degree in construction and facility management, with the objective of training professionals in the application of the BIM; it covers all lifecycles of a building from project to work execution and exploitation, including the BIM software (Navisworks, ArchiCAD, Allplan and AECOsim) training and information management needs in multitasking. Concerning civil engineering, the Polytechnic University offers a smart construction/BIM unit within the project management field that allows students to exchange and interconnect with international work based in BIM; namely, the unit addresses the management of BIM models and interference detection in follow-up work, monitoring, implementation and workflows [26]. At the University of Lisbon, in the integrated master's degree in civil engineering, an initiation to the BIM concept and practice is introduced during the bachelor's cycle in the computer-aided drawing unit, but at this early stage, only the generation of the architectural and structural components of a BIM model (Revit) is taught. In addition, the department offers short courses in continuous training and workshops for students within a forum setting. Numerous MSc theses using the BIM methodology have been developed over the past 10 years on a wide range of topics [27].

Different authors have promoted a collaborative environment for introducing BIM into undergraduate and postgraduate courses, with some success $[12,18,19,28-30]$. However, most documented cases of the academic implementation of BIM focus primarily on the implementation strategy [29], the tools in use [30], or the industry's perception of this implementation in the university setting [31-39], with relatively few studies on students' perceptions of this implementation [40-44]. The present study analyses the implementation of BIM within a collaborative learning methodology for curriculum subjects at an industrial engineering school. The research is mainly focused on student perceptions while using BIM to develop an industrial technology project.

\section{Materials and Methods}

The strategy followed in the present didactic experiment, which was applied in the industrial engineering program at a school of industrial engineering to incorporate BIM into technical projects, is based on the collaborative learning methodology. As such, the adaptation of the BIM methodology for training in technical projects towards different degrees in industrial engineering has been proposed in two phases [45] (Figure 1).

Phase 1 The basic technical project subject was developed as part of the mandatory training plan for all degrees in industrial engineering during the basic technical project course (second year, fourth quarter). All degrees in industrial engineering include this course as part of their mandatory training. For this class, the necessary BIM concepts and tools are introduced gradually so that students can perform visualization tasks with sufficient autonomy $(\mathrm{V})$, as well as 3D modeling $(\mathrm{M})$ and simulation (S), in BIM. For all degrees, BIM use has been voluntary, except for the degree in industrial technology. For this degree, the use of BIM is mandatory during the last academic year. As a result, and in parallel with the levels defined in BIM and upon completing this first phase, the student could gain BIM knowledge and experience ranging from a level of BIM maturity zero to a level of BIM maturity $1-2[36,46,47]$.

Phase 2 The expert technical project course was developed only within the training plan for the degree in industrial technology as part of the mandatory expert the technical project course (fourth year, eighth quarter), together with activities of greater specialization for the end-of-degree project course (fourth year, eighth quarter) for all degrees and other training activities aimed at creating working teams of students and teachers for participation in BIM meetings. These latter activities are not included as part of the mandatory degree training in industrial engineering. 


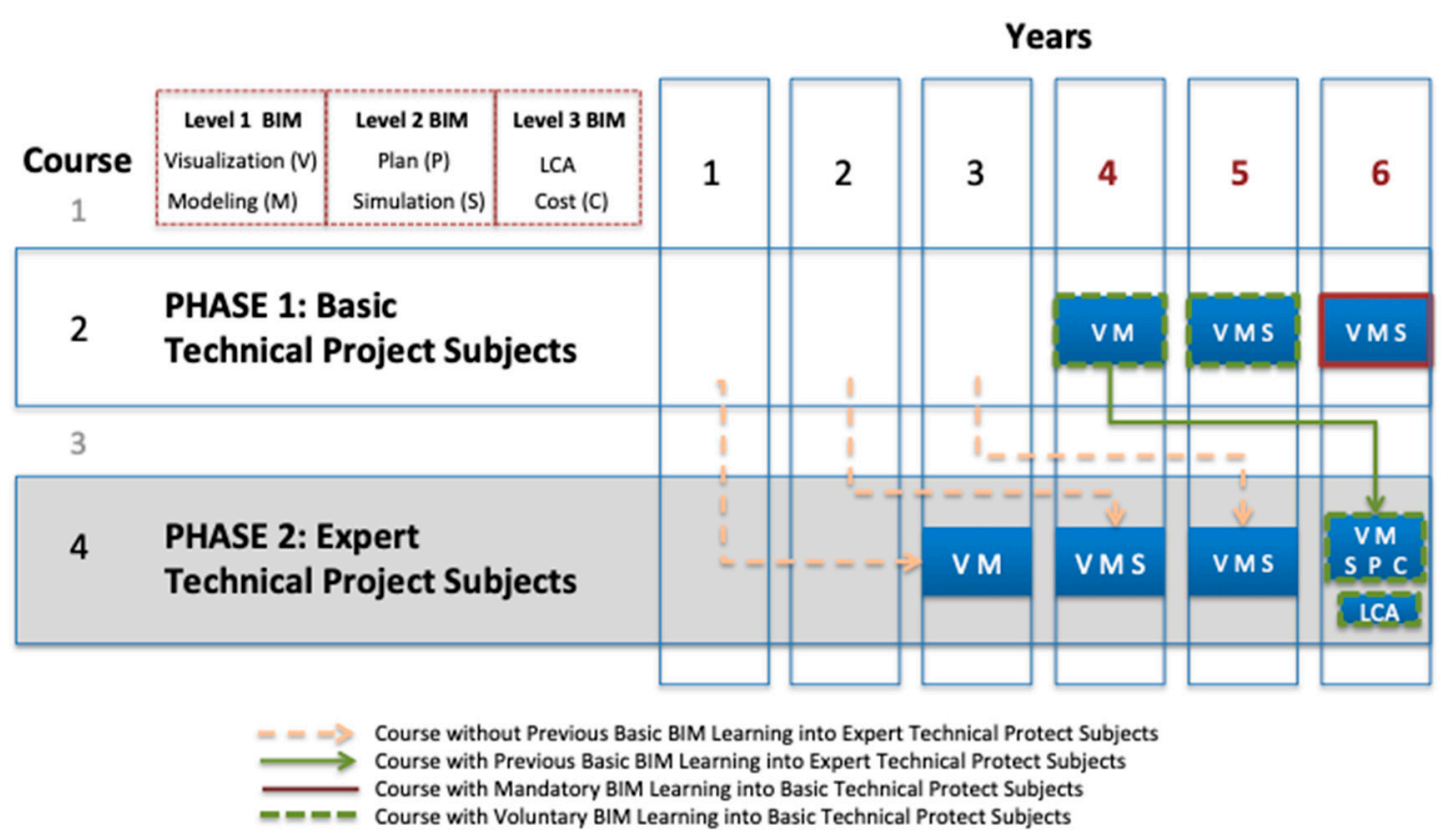

Figure 1. Flow chart for the building information modeling (BIM) implementation for a technical project course.

\subsection{BIM Implementation in Project Classes}

The curricula for degrees in industrial engineering at the School of Industrial Engineering where BIM was implemented are organized into four courses, which constitute eight quarters of teaching. For these courses, 240 European Credit Transfer and Accumulation System (ECTS) credits are taught at a rate of 60 credits per academic year. The BIM implementation was performed during the practical portion of the mandatory fourth-year technical project class for the degree in industrial technologies (6.0 ECTS credits). The practical portion amounts to $50 \%$ of the ECTS credits of the total required for the subject.

The class on expert technical projects for the industrial technologies engineering degree was chosen because the degree brings together knowledge of the various engineering technological fields in the industry (mechanical, electrical, electronics, automatics, chemical, and organizational) that do not exist within the curriculum of the master's degree in industrial engineering for any technical project class. In addition, the timing of the class within the degree course (last year, eighth quarter) is such that the students will have already acquired almost all of their degree skills before taking the class. At this second level, the skills necessary for tasks related to visualization (V), 3D modeling (M), and simulation (S) are mature, and the BIM tasks of planning (P), costs $(\mathrm{C})$, and other specific tasks, such as life-cycle analysis (LCA), are introduced so that students who are completing the first and second phases can acquire the knowledge and experience at the level of BIM maturity 2-3.

Historically, technical project drafting falls within the scope of traditional activities for industrial engineers. These two chosen topics involve the specific skill of the "Capacity for drafting, signing, and developing projects in the field of industrial engineering whose purpose is the construction, reform, repair, conservation, demolition, manufacture, installation, assembly, or operation of structures, mechanical equipment, energy facilities, electrical and electronics installations, industrial facilities and plants, and manufacturing and automation processes."

The students started out with the fundamental skills and expertise to perform 2D representation, probably due to their training in preliminary courses in the mandatory subjects graphic expression and computer-aided drawing. However, they needed to take an important step when facing a 3D model for the first time. The transition from a 2D model to a 3D model was an important objective in Phase 1 BIM. 
Within the different practical tasks that students have to perform in technical project classes, they create a model in which different facilities will be implemented depending on the type of industrial facility being planned. After the models are created, they can be used, for example, to detect geometric intersections or clashes. All the tasks were designed to give the students a clear vision of what BIM means rather than focusing only on the tools being used. To implement this learning, different types of activities were developed depending on the student group's phase at the moment, such as classroom classes, follow-up of laboratory work, and specific tutorials and seminars especially for implementing the facilities in the model. Many of these activities were more common in Phase 2 BIM. As described by Caballero, Pérez, Fernández-Coppel, and Lite (2017), the objective of the implementation was that during the project life-cycle, the student would to be able to create BIM models, including facilities (mechanical, electrical, and plumbing) and would be able to apply IFC ("Industry Foundation Classes") standards [21].

The exploration performed during the BIM implementation involves only the development of the practical activities that are performed in correspondence with the mandatory expert technical project course taught during the fourth year of the industrial technologies degree (expert technical project course). The BIM implementation in technical project courses takes place only during the practical part of the course, using the collaborative methodology described by Blanco, Sanchez-Lite, and Garcia [46]. This methodology is based on a sequence of activities to achieve part of the objectives that allow the definition of the technical industrial project that the student must deliver for evaluation within the course. The sequence of activities takes place over 15 sessions for both basic and expert courses, with a duration of $2 \mathrm{~h}$ per session. In each of the 15 practical sessions, the student completes his or her project by solving the different technical issues that are presented.

The data considered for the students' perceptions were obtained from the fourth-year technical project class for the degree in industrial technologies (expert technical project course) over the last four years (see Figure 1). In relation to the resources used for implementation, the ICT tools described by Blanco et al. (2015) for the application of collaborative methodologies for technical project course [48] along with software tools commonly used in BIM academic environments (Revit Autodesk (C), Revit MEP Autodesk (C), RevitStructure Autodesk (C), Factory Module Autodesk (C, Navisworks Autodesk (C) (Autodesk, New York, NY, USA, R2019), CIPE CAD METAL @ , CIPE Arquimedes (C (CYPE Ing. SA, Alicante, Spain, R2019), MagiCAD Autodesk (C) MagiCAD (MagiCAD Group, London, UK, R2019), and BIMVision (C) (Datacomp, Cracow, Poland, R2019) [49-51] focused on the BIM teaching and not on the software tool, as advised by Sacks and Barak [52].

\subsection{Approach for the Analysis of Student Perceptions of BIM}

An important factor in feedback following academic implementation is the students' perspective [53]. The aim of this work was to evaluate the student perceptions of the advantages and difficulties of incorporating BIM into the formal teaching system as part of the degree in industrial engineering.

As Figure 2 shows, the study was developed in three steps. In the first step, the students' perceptions of the BIM methodology and the use of the 3D tool were analyzed. In the second step, the students' opinions regarding the use of BIM and the acquisition of skills were analyzed. Finally, in the third step, possible relationships between the students' overall satisfaction, the use of the BIM methodology and the 3D tool and the acquisition of competence were studied.

To explore the student perceptions, a Likert survey with five levels was applied. The survey was administered only to students enrolled in the fourth-year coursework for a degree in industrial technologies (expert technical project course). This degree is an industrial engineering degree offered within the School of Industrial Engineering. Table 1 shows the 20 survey questions, which were divided into three sections: The first section focused on the BIM technological tool; the second referred to the chosen 3D design tool; and the third tried to collect an overall evaluation of the students' satisfaction in relation to their perceptions of their use of BIM and acquired skills, together with 
their global vision of the subject. These questions were adapted to expert industrial technology projects from different studies, taking into account the advantages and barriers of the academic BIM implementation $[7,13,15,33-39]$.

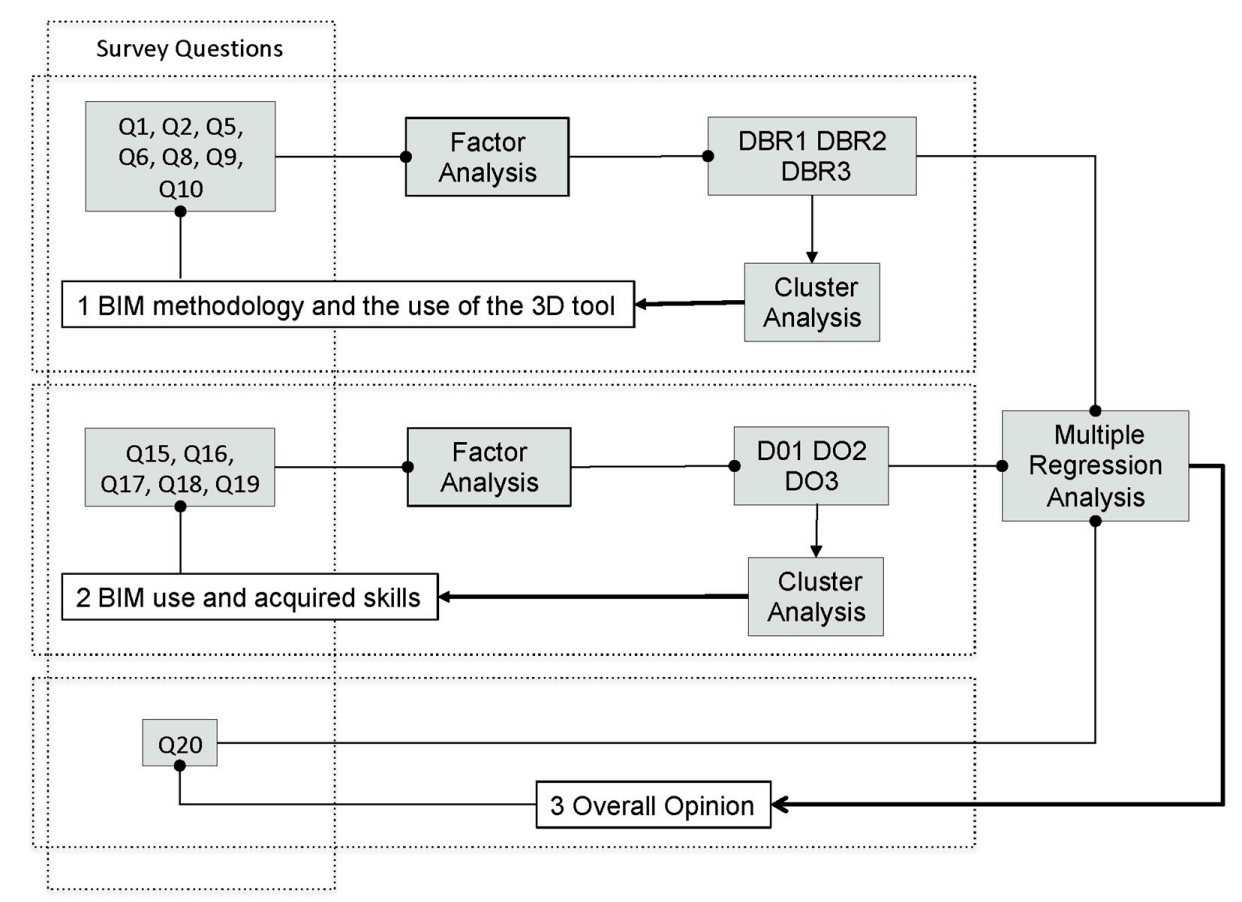

Figure 2. Flow chart of the BIM implementation for a technical project course.

Table 1. Questions about the BIM Implementation.

$\begin{array}{cc}\text { Question } & \text { Regarding } \\ \text { Q1. Do you consider BIM modeling useful for projects? } & \text { BIM } \\ \text { Q2. Rate your personal assimilation of the BIM concept and its application } & \text { BIM } \\ \text { Q4. Level of BIM integration into industrial engineering projects } & \text { BIM } \\ \text { Q5. Rate your interest in and motivation for using BIM after this module } & \text { BIM } \\ \text { Q6. Rate your interest in groupwork using the BIM methodology } & \text { BIM } \\ \text { Q7. Rate the possibility of working with BIM from different geographical locations } & \text { BIM } \\ \text { Q8. Do you think REVIT is an intuitive and affordable piece of software? } & \text { Software used } \\ \text { Q9. Is the amount of time spent on REVIT proportional to the degree of acquired learning? } & \text { Software used } \\ \text { Q10. Do you think that the project has given you a sufficient level of skill to be able to use } & \text { Software used } \\ \text { Q11. What additions do you think the REVIT MEP needs? } & \text { Software used } \\ \text { Q12. Rate the difficulty of learning how to use REVIT } & \text { Software used } \\ \text { Q13. What level of options does REVIT provide for working in a group? } & \text { Software used } \\ \text { Q14. How do you think BIM improves your CV as an engineer? } & \text { Overall opinion } \\ \text { Q15. Rate the use of BIM in the context of this module } & \text { Overall opinion } \\ \text { Q16. How much does this module increase your level of competence as an engineer? } & \text { Overall opinion } \\ \text { Q17. To what degree has this module contributed to independent learning? } & \text { Overall opinion } \\ \text { Q18. What level have you reached in terms of your decision-making responsibility as an } & \text { Overall opinion } \\ \text { Q19. To what degree has the module contributed to the development of skills related to } & \text { Overall opinion } \\ & \text { groupwork? } \\ \end{array}$

Three control questions were incorporated into the sections related to BIM and the use of the 3D design tool (questions 3, 4, and 11) to ensure the students' interest and the reliability of their answers. To ensure a degree of consistency in the students' answers, control questions were introduced within 
each of the sections (questions $6,7,8,9,10,12,13,14,16$, and 19). Opposing results between questions 6 and 7,10 and 12, 13 and 19, or 14 and 16 would force the researchers to disregard the responses of that sample. Most samples were collected by the teacher during the face-to-face delivery of the practical part of the course through interviews between students and teachers rather than with a paper survey because it was easier to obtain student views this way and because it encouraged a higher degree of student participation.

To reduce the number of variables, a statistical analysis was performed using the exploratory factor analysis [54]. Since the scores were coded on a noncontinuous scale, the factor analysis was calculated using the polychoric correlation matrix. The adequacy of the dispersion matrix was determined using the Kaiser-Meyer-Olkin index (KMO). The number of factors (or components) was selected by applying the Guttman-Kaiser rule, the percentage of cumulative variability ( $\geq 80 \%$ in total), and Cattell's scree test. The extraction method was the principal component analysis (PCA), and the solution was rotated using varimax rotation to achieve greater simplicity and better factor identification [55]. The scientific literature shows good results when using this approach [56,57].

When considering the factor analysis results, to classify the courses under study, a hierarchical ascendant classification (agglomerative hierarchical clustering, AHC) was used [58,59]. The AHC analysis follows the factor analysis as a successful approach according to different studies [60]. AHC was performed using the Mahalanobis distance as a measure of distance to reduce the influence of outliers and possible variable correlations [61]. The unweighted pair-group average was used as the agglomeration method. Using the Friedman test [62] and the Nemenyi procedure [59], the existence of statistically significant differences between the cluster means was evaluated, taking into account the variables chosen for the evaluation.

Finally, to identify possible relationships between the student satisfaction with the BIM implementation (question 20: Overall opinion) and the factors obtained through the factor analysis, a multiple regression analysis was performed (Figure 2).

\section{Results}

To explore the perceptions of students in the fourth-year expert technical project course, the last four academic years were evaluated. The BIM use was mandatory starting in the first academic year. The total number of students for the four academic years was 86 .

The student point of view was analyzed during the fourth-year expert portion of the last academic courses using the previously described methodology. The total number of students was 86 , for a total of $64 \%$ valid samples. The results obtained for the questions posed after the control questions were eliminated are shown in Table 2.

Table 2. Phase 2: Descriptive statistics of the students' views regarding BIM.

\begin{tabular}{cccccccc}
\hline Question & Min. & Max & Freq. of Min. & Freq. of Max. & Median & Mean & $\begin{array}{c}\text { Stand. Deviation } \\
(\mathbf{n}-\mathbf{1})\end{array}$ \\
\hline Q1 & 2 & 5 & 12 & 9 & 4.000 & 3.491 & 1.016 \\
Q2 & 1 & 5 & 2 & 5 & 3.000 & 3.200 & 1.026 \\
Q5 & 1 & 5 & 6 & 8 & 3.000 & 3.109 & 1.227 \\
Q6 & 2 & 5 & 6 & 10 & 3.000 & 3.564 & 0.918 \\
Q8 & 1 & 3 & 17 & 20 & 2.000 & 2.055 & 0.826 \\
Q9 & 1 & 4 & 13 & 3 & 2.000 & 2.255 & 0.886 \\
Q10 & 1 & 4 & 15 & 7 & 2.000 & 2.255 & 1.004 \\
Q15 & 1 & 5 & 1 & 14 & 4.000 & 3.855 & 0.891 \\
Q16 & 2 & 4 & 7 & 21 & 3.000 & 3.255 & 0.673 \\
Q17 & 2 & 5 & 3 & 7 & 4.000 & 3.800 & 0.730 \\
Q18 & 2 & 5 & 5 & 7 & 4.000 & 3.582 & 0.832 \\
Q19 & 2 & 5 & 12 & 2 & 3.000 & 3.309 & 0.858 \\
Q20 & 2 & 5 & 7 & 2 & 3.000 & 3.345 & 0.751 \\
\hline
\end{tabular}




\subsection{BIM Methodology and the Use of the 3D Tool}

Using the responses to questions Q1, Q2, Q5, Q6, Q8, Q9, and Q10 of Table 2, the students' views regarding the $\mathrm{BIM}$ methodology and the use of the $3 \mathrm{D}$ tool in the practical part of the course were studied. A factor analysis was performed to reduce the number of variables. The number of factors extracted was three (the following were considered: Guttman-Kaiser rule, percentage of cumulative variability ( $\geq 80 \%$ in total), and Cattell's scree test), with the factors explaining $94.91 \%$ of the variance. After varimax rotation, it could be observed that factor DBR1 was associated with variables Q1 and Q2; factor DBR2 was associated with variables Q5, Q6, and Q9; and factor DBR3 was associated with variables Q8 and Q10 (Table 3). The obtained KMO index was 0.742, and Cronbach's alpha was 0.962. The factor loadings and the scree plot are shown in Figure 3.

Factor DBR1 can be interpreted as the "level of utility and assimilation of BIM by the student"; factor DBR2 can be described as "the interest in BIM and the effort required to learn the tool after the experience"; and factor DBR3 can reflect the "complexity and level of learning of the tool."

An AHC analysis was performed using factors DBR1, DBR2, and DBR3 when the students were distributed into six classes. Figure 4 shows the dendrogram, the within-class variance according to the number of classes, and the cluster profile.

Table 3. Factor analysis questions about BIM: Factor pattern after varimax rotation.

\begin{tabular}{cccc}
\hline Question & DBR1 & DBR2 & DBR3 \\
\hline Q1 & 0.757 & 0.462 & 0.416 \\
Q2 & 0.840 & 0.364 & 0.352 \\
Q5 & 0.501 & 0.622 & 0.552 \\
Q6 & 0.405 & 0.848 & 0.224 \\
Q8 & 0.310 & 0.263 & 0.903 \\
Q9 & 0.285 & 0.870 & 0.335 \\
Q10 & 0.536 & 0.429 & 0.665 \\
\hline
\end{tabular}

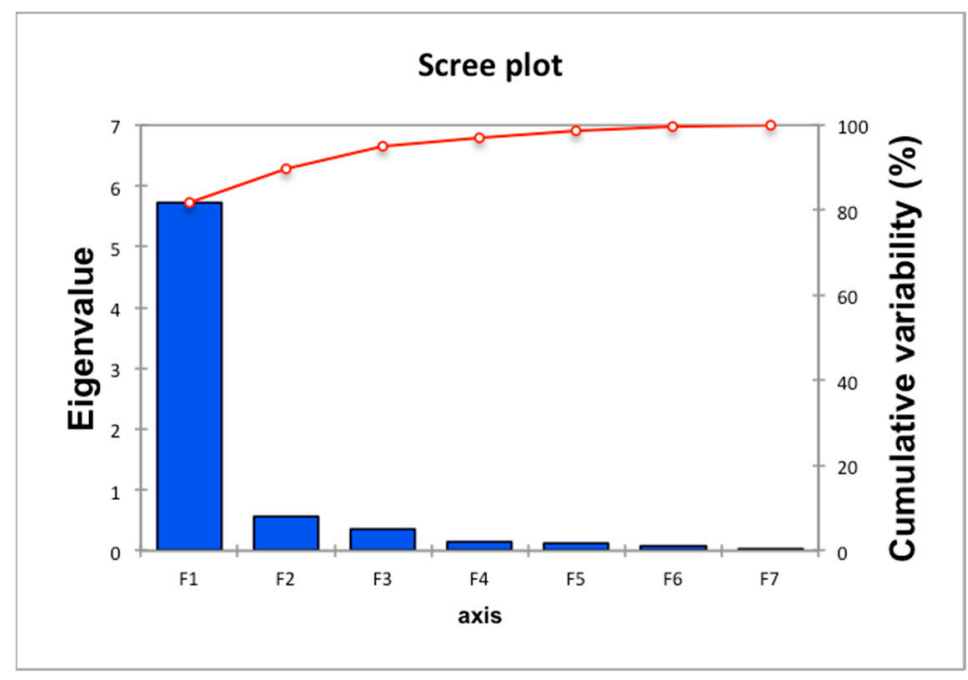

(a)

Figure 3. Cont. 


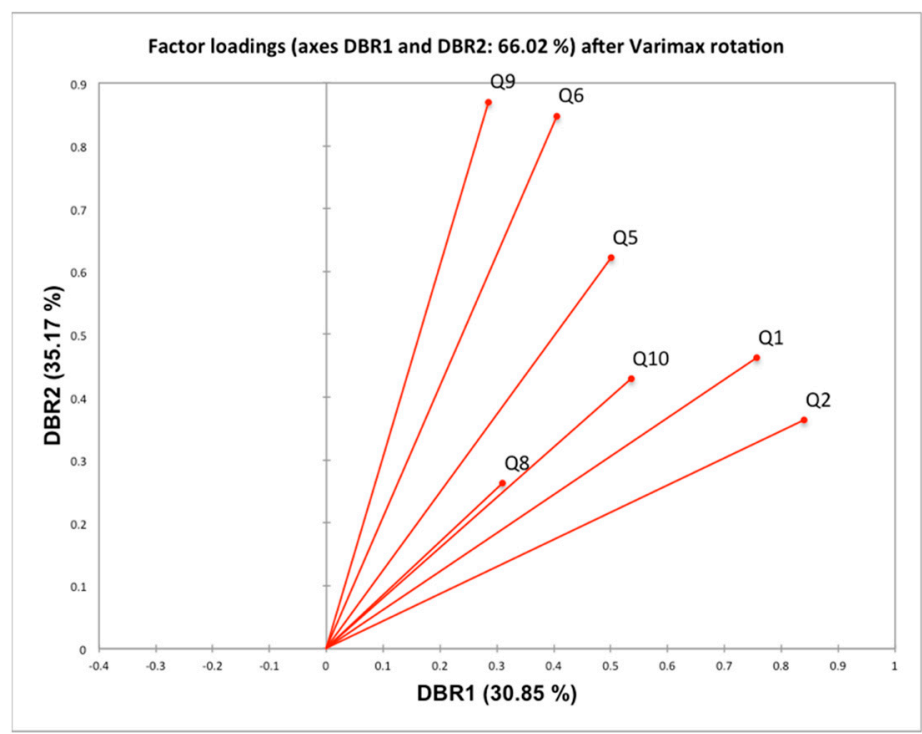

(b)

Figure 3. Factor analysis: Factor loadings after varimax rotation. Students views of the use of BIM during the second implementation phase. (a) Scree plot; (b) factor loadings after varimax rotation.

The full dendrogram displays the progressive clustering of the samples. The dotted line represents the truncation, leading to six groups: Cluster 1 (displayed in blue), cluster 2 (displayed in violet), cluster 3 (displayed in red), cluster 4 (displayed in dark green), cluster 5 (displayed in purple), and cluster 6 (displayed in green). The horizontal axis represents the samples, while the vertical axis represents the dissimilarity coefficients. The samples are identified by two numbers; the first represents the year, and the second represents the order number.

The results reflect a within-class variance of $35.00 \%$ and a between-class variance of $64.99 \%$. Clusters 1 and 5 had the highest number of students ( $29.1 \%$ and $27.3 \%$, respectively), followed by 3 $(16.4 \%), 6(10.9 \%), 2(9.0 \%)$, and $4(7.3 \%)$.

Cluster 1 ( $29 \%$ of the samples) contains students with a high perception of the level of BIM utility and their own learning outcomes, defining the tool used for the BIM implementation as intuitive and easy to learn, while Cluster 5 ( $27 \%$ of the samples) groups students with a low perception of the BIM utility level and their own learning outcomes, defining the tool used for the BIM implementation as nonintuitive and complex to learn. Cluster 3 (16.4\% of the samples) groups students with a high perception of the BIM utility level and their own learning outcomes who considered the tool used for the BIM implementation as moderately intuitive and complex to learn.

When analyzing Cluster 2, it can be observed that $9 \%$ of the sample, which defined the tool used for the BIM implementation as not very intuitive and complex to learn, showed a high opinion regarding the usefulness of BIM after implementation. Cluster 4 shows that $7 \%$ of students did not consider BIM useful for performing technical projects, considered the tool moderately complex, and evaluated BIM after studying the subject as having moderate utility. Cluster 6 (10.9\% of the sample) represents students who consider the tool complex and perceive BIM as unhelpful.

The Friedman test of the six clusters reflected a $p$-value $<0.001$. Since the computed $p$-value was lower than the significance level alpha $=0.05$, the null hypothesis $\mathrm{H} 0$ should be rejected. The samples did not come from the same population. The multiple comparison post hoc analysis reflected a $p$-value $<0.001$ for the qualification variables, indicating the presence of statistically significant differences between the clusters with respect to all the classification variables. 


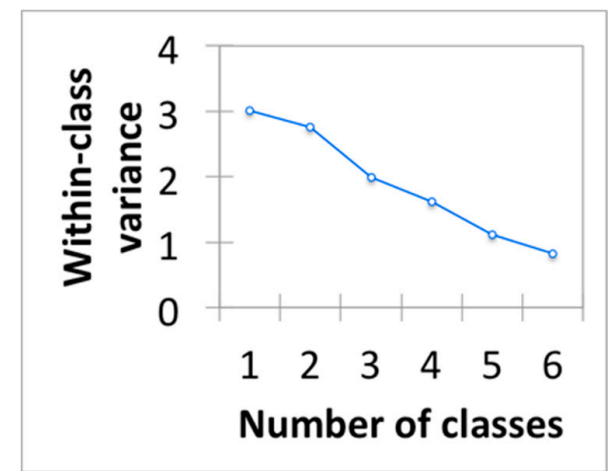

(a)

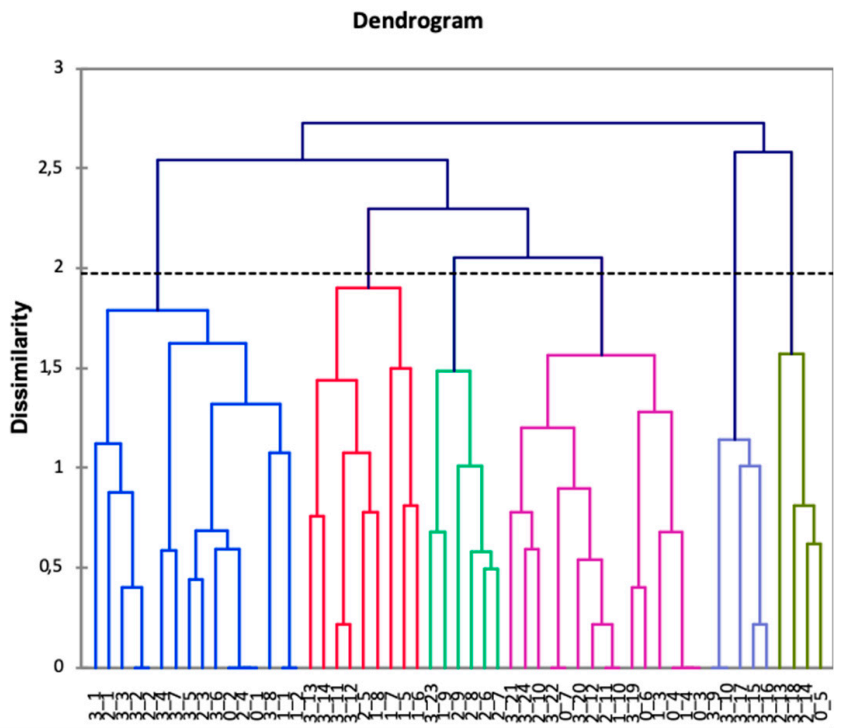

(b)

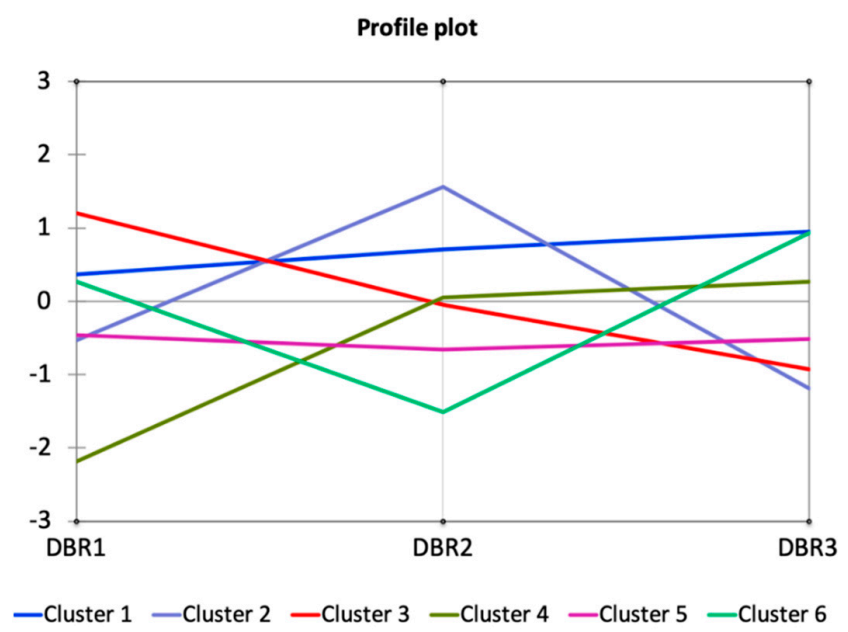

(c)

Figure 4. Agglomerative hierarchical clustering (AHC): Students' views on the use of BIM and the three-dimensional (3D) tool during the second implementation phase. (a) Evolution of variance; (b) dendrogram and (c) profile plot.

\subsection{BIM Use and Acquired Skills}

Using questions Q15: Q16, Q17, Q18, and Q19 in Table 2, the students' perceptions of the contribution of their BIM use and acquired skills was studied. A factor analysis was performed to reduce the number of variables. The number of extracted factors was three, and the factors explained 
91.26\% of the variance. After varimax rotation, factor DO1 was observed to be associated with variable Q19; factor DO2 was associated with variables Q15 and Q17; and factor DO3 was associated with variables Q16 and Q18 (Table 4). The factor loadings are shown in Figure 5. The obtained KMO was 0.843, and Cronbach's alpha was 0.909. The factor loadings and the scree plot are shown in Figure 4.

Table 4. Factor analysis questions about the BIM contribution and acquired skills: Factor pattern after varimax rotation.

\begin{tabular}{cccc}
\hline Question & DO1 & DO2 & DO3 \\
\hline Q15 & 0.440 & 0.709 & 0.467 \\
Q16 & 0.215 & 0.327 & 0.874 \\
Q17 & 0.238 & 0.912 & 0.283 \\
Q18 & 0.520 & 0.308 & 0.663 \\
Q19 & 0.895 & 0.291 & 0.269 \\
\hline
\end{tabular}

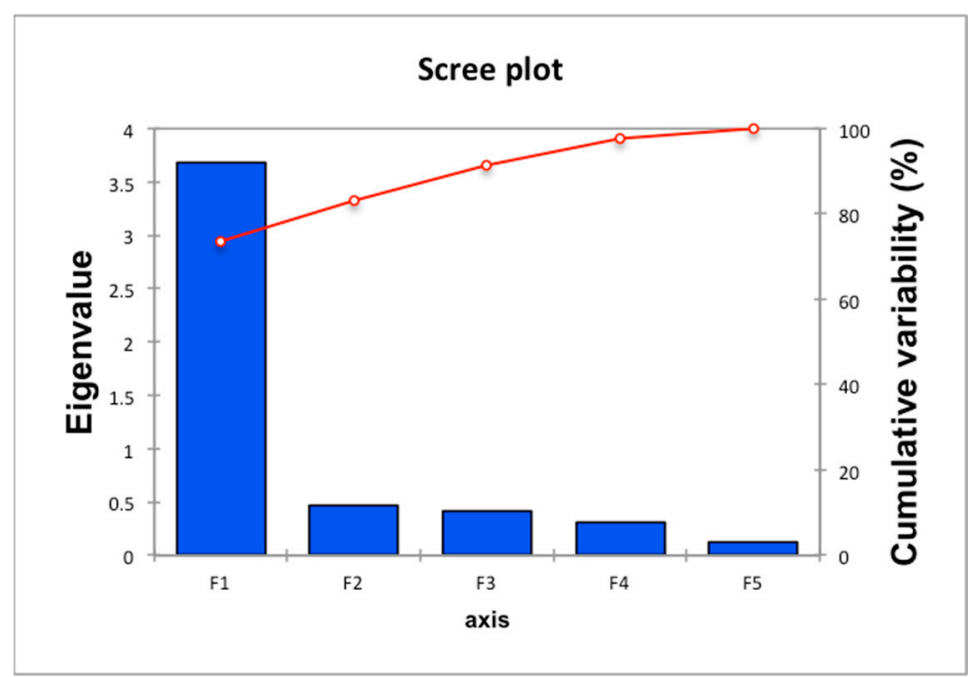

(a)

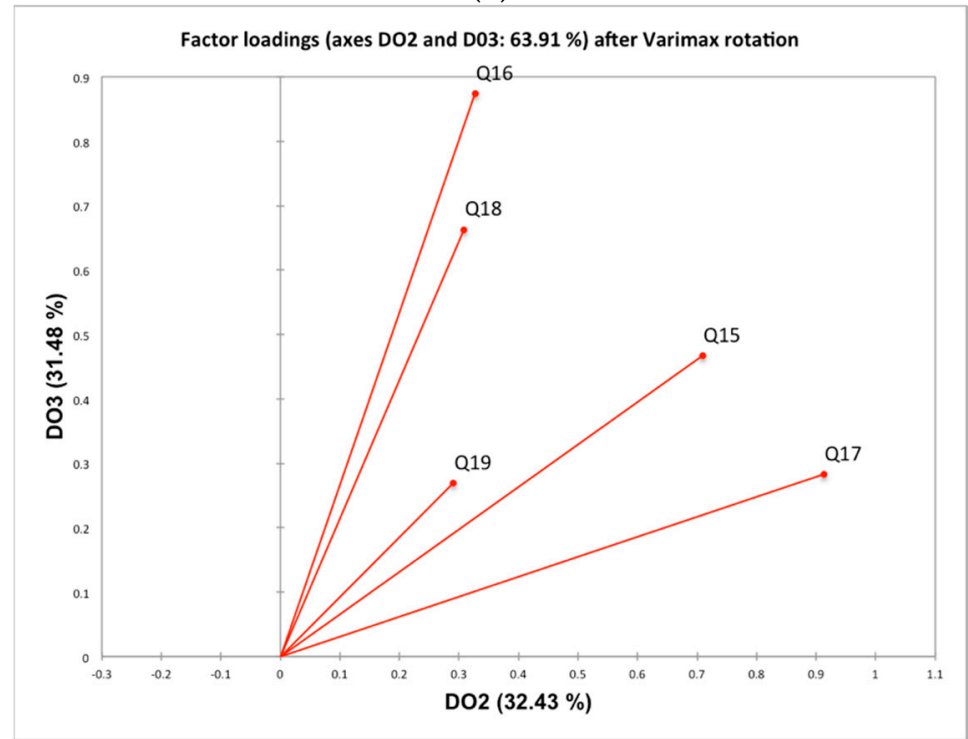

(b)

Figure 5. Factor analysis: Students' opinions regarding the use of BIM and the skills acquired during the second implementation phase. (a) Scree plot; (b) factor loadings after varimax rotation. 
The DO1 factor could be interpreted as "BIM's contribution to teamwork", DO2 as "BIM's contribution to the technical project subject", and DO3 as "BIM's contribution to the development of the global skills of an industrial engineer".

An AHC analysis was performed using factors DO1, DO2, and DO3, distributing the students into six classes. Figure 6 shows the dendrogram, the within-class variance according to the number of classes, and the profile. The full dendrogram displays the progressive clustering of samples. The dotted line represents the truncation, which led to six groups: Cluster 1 (displayed in dark green), cluster 2 (displayed in violet), cluster 3 (displayed in purple), cluster 4 (displayed in red), cluster 5 (displayed in blue), and cluster 6 (displayed in green). The horizontal axis represents the samples, while the vertical axis represents the dissimilarity coefficients. The samples are identified by two numbers; the first represents the year, and the second represents the order number.

The results reflect a within-class variance of $35.01 \%$ and a between-class variance of $64.99 \%$. Clusters 1 and 3 had the highest number of students (38\% and 30\%, respectively), followed by $2(15 \%)$, $4(9 \%), 5(4 \%)$, and $6(4 \%)$.

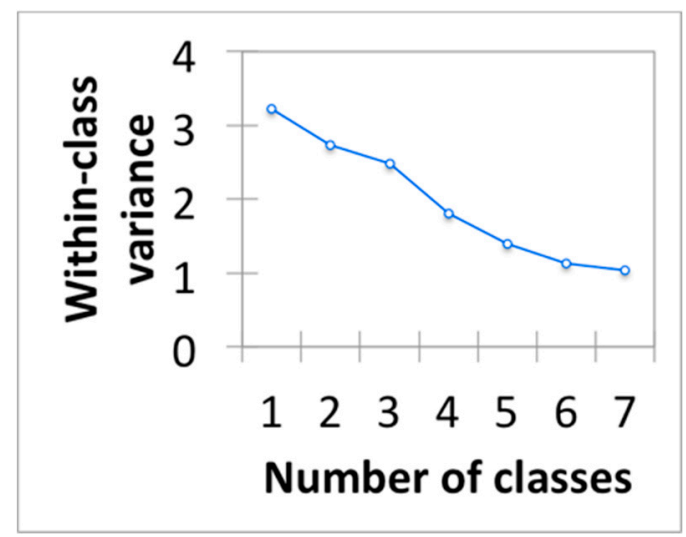

(a)

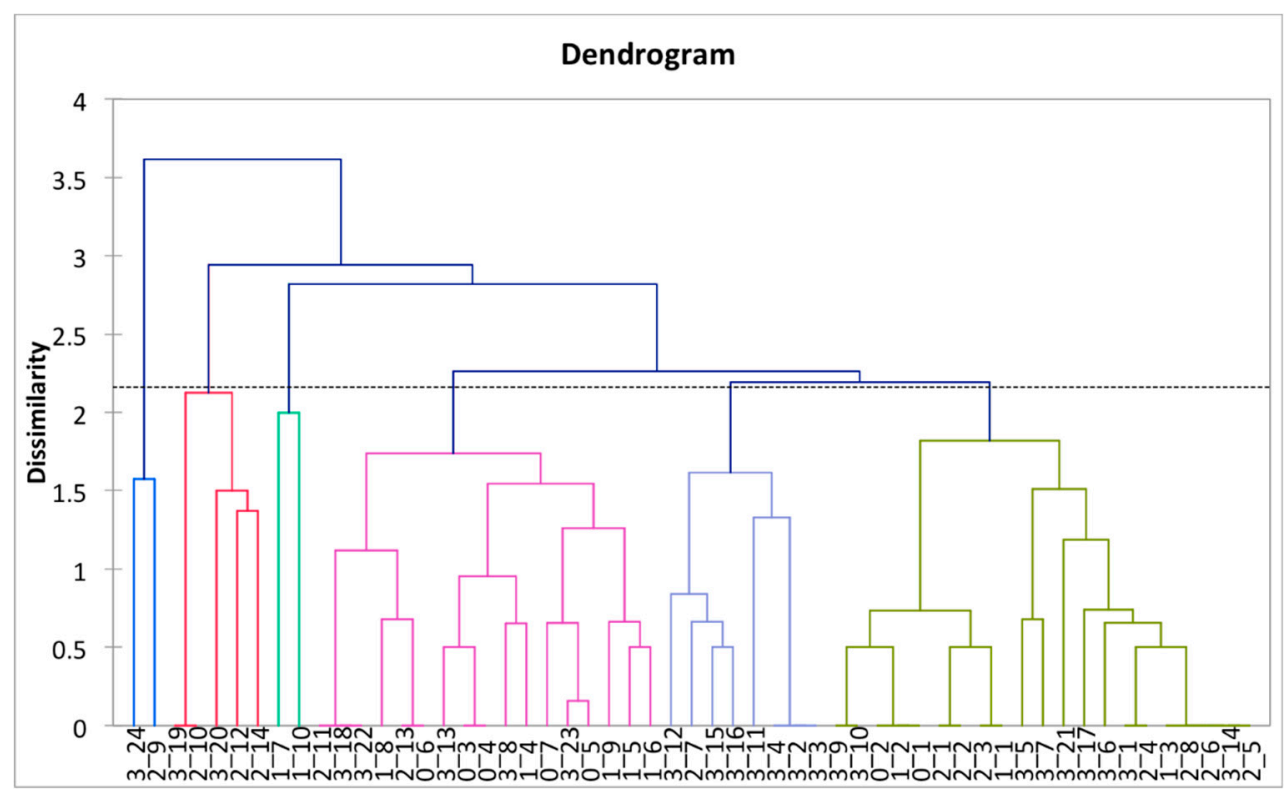

(b)

Figure 6. Cont. 


\section{Profile plot}

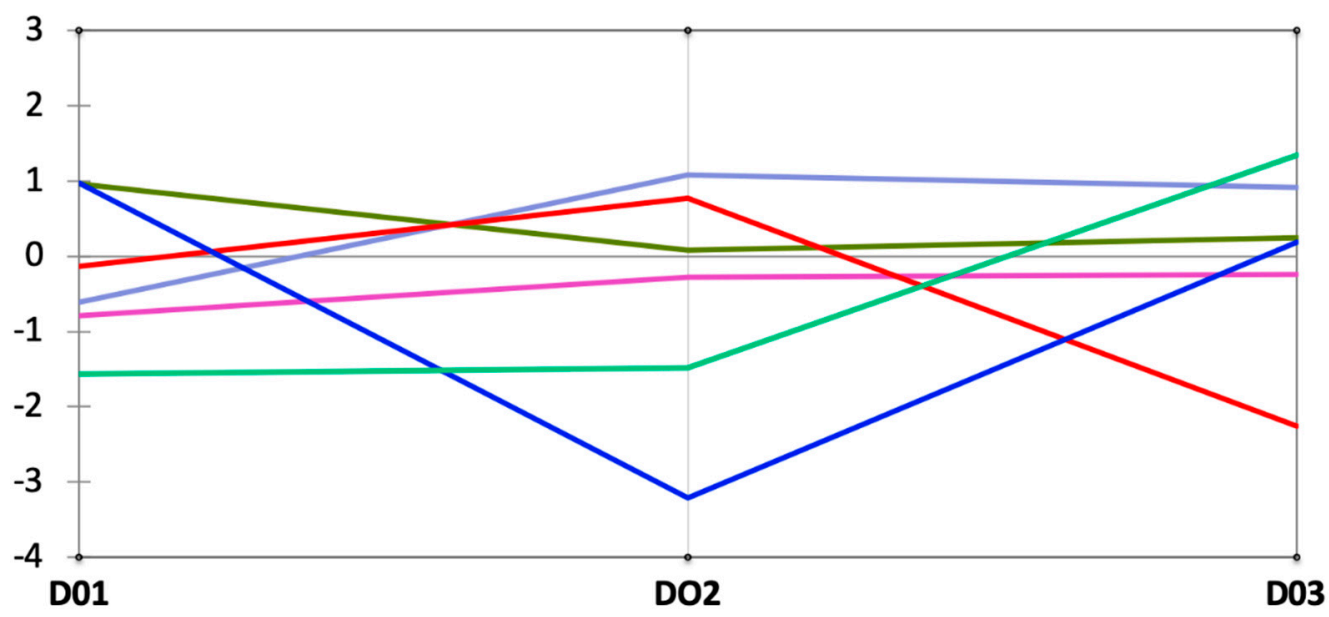

-Cluster 1 -Cluster 2 -Cluster 3 -Cluster 4 -Cluster 5 -Cluster 6

(c)

Figure 6. Agglomerative hierarchical clustering (AHC): Students' opinions regarding the use of BIM and the skills acquired during the second implementation phase. (a) Evolution of variance; (b) dendrogram and (c) profile plot.

Cluster 1 (38\% of the sample) groups the students with a high average perception of BIM's contribution to teamwork (variable DO1) and average values regarding BIM's contribution to the technical project subject (variable DO2) and its contribution to the skills of an industrial engineer (variable DO3). Cluster 3 ( $30 \%$ of the sample) groups the students who did not consider BIM's contribution to teamwork (DO1) important and considered the other variables moderately important. Cluster 2 ( $15 \%$ of the sample) contains students who perceived that BIM had an important contribution to the technical project course (DO2) and to the skills of an industrial engineer (DO3) but did not consider BIM's contribution to teamwork (DO1) so important. Cluster 4 (9\% of the sample) contains students who consider BIM's overall contribution to the skills of an industrial engineer to be the least important (DO3), its contribution to the technical project subject (DO2) important and its contribution to teamwork (DO1) moderately important. Cluster 5 ( $4 \%$ of the sample) groups students who considered BIM's contribution to the technical project subject (DO2) least important and considered only BIM's contribution to teamwork important (DO1). Finally, Cluster 6 ( $4 \%$ of the samples) groups students that considered BIM's contribution to teamwork (DO1) least important and did not consider BIM's contribution to the technical project course (DO2) important, although they considered BIM's overall contribution to the skills of an industrial engineer (DO3) important. It is convenient to keep in mind that these last two classes contained few samples.

The Friedman test of the six clusters reflected a $p$-value $<0.001$. Since the computed $p$-value was lower than the significance level alpha $=0.05$, the null hypothesis $\mathrm{H} 0$ should be rejected. The samples did not come from the same population. The multiple comparison post hoc analysis reflected a $p$-value $<0.001$ for the qualification variables, indicating that there are statistically significant differences between the clusters with respect to all the classification variables.

\subsection{Overall Opinion: Global Satisfaction, BIM, 3D Tool and Acquired Skills}

Taking the Q20 variable as a dependent variable and factors DBR1, DBR2, DBR3, DO1, D02, and D03 as independent variables, a multiple regression analysis was performed. 
The resulting model was (1):

$$
\mathrm{Q} 20=3.340+0.376 \times \mathrm{DBR} 1+0.289 \times \mathrm{DBR} 2+0.220 \times \mathrm{DBR} 3
$$

The $p$-values for the t-test suggest that DBR1 $(p<0.001)$, DBR2 $(p<0.001)$, and DBR3 $(p=0.012)$ were significantly different from zero. The standardized coefficients showed that the variable of greatest influence was DBR1, followed by DBR2 and DBR3. The value of R2 was 0.43 , indicating that approximately $43 \%$ of the variability of the satisfaction variable was explained by factors DBR1, DBR2, and DBR3. The mean square error (MSE) was 0.327 . The $p$-value for the analysis of the variance F-test ( $p<0.001$, significance level of 5\%) suggest that the model containing DBR1, DBR2, and DBR3 is more useful for predicting Q20 than not taking the three predictors into account. The VIF coefficient shows the absence of multicollinearity problems in the model.

It was possible to obtain a more complex nonlinear model with all the variables. The model was (2):

$$
\begin{gathered}
\mathrm{Q} 20=3.368+0.115 \times \mathrm{DBR} 10.043 \times \mathrm{DBR} 20.003 \times \mathrm{DBR} 3+0.273 \times \\
\mathrm{DO} 1+0.408 \times \mathrm{DO} 2+0.313 \times \mathrm{D} 03+0.048 \times \mathrm{DBR} 1 \times \mathrm{DR} 10.070 \times \\
\mathrm{DBR} 2 \times \mathrm{DR} 2+0.045 \times \mathrm{DBR} 3 \times \mathrm{DBR} 3+0.030 \times \mathrm{DO} 1 \times \mathrm{DO} 1+0.072 \times \\
\mathrm{DO} 2 \times \mathrm{DO} 2-0.115 \times \mathrm{D} 03 \times \mathrm{DO} 3 .
\end{gathered}
$$

The value of $\mathrm{R} 2$ was 0.602 , indicating that approximately $60 \%$ of the variability in the satisfaction variable was explained using all the factors posed by the model. The MSE was 0.291.

\section{Discussion}

When the results obtained here are analyzed to determine the students' views, it can be seen that the factor analysis of the questions referring to BIM and the tool in use shows three factors. The diagram on factor loadings in the DBR1, DBR2 plane shows a high correlation between the ease of use of the tool (Q8) and learning $(\mathrm{Q} 10)$. There was also a direct correlation between the BIM utility perceived by the student $(\mathrm{Q} 1)$ and the student's evaluation of the BIM learning level (Q2) and between the interest and motivation in relation to BIM after completing the course (Q5) and the complexity of the tool in use (Q8). Finally, it could be interpreted that the complexity of the tool in relation to the time spent learning (Q9) within the chosen BIM implementation method has a direct relationship with the effects of BIM on improving teamwork (Q6).

A cluster analysis performed with the data obtained regarding the views of students in the mandatory fourth-year course for the degree in industrial technologies using the questions related to BIM and the tool in use (REVITC) showed six different clusters. The differences between the clusters were statistically significant with respect to the classification variables.

In observing the results of the factor analysis for the questions related to the students' views regarding BIM's contributions, the factor loading diagram in the DO1, DO3 plane shows a direct correlation between the utility of BIM for developing the practice of the course (Q15) and the development of teamwork skills (Q19) and autonomous learning (Q17). There was also a direct correlation between the acquisition of skills (Q16) and the development of skills related to the decision-making processes of an industrial engineer (Q18).

The cluster analysis using the data obtained regarding the responses of students in Phase 2 BIM (a mandatory fourth-year course for the degree in industrial technologies) to the questions related to BIM's contribution showed six different clusters with statistically significant differences with respect to the classification variables.

If we compare the results of the two cluster analyses, approximately $60 \%$ of the sample in the AHC Class 1 (AHC-Opinion), based on the variables DO1, DO2, and DO3, are contained in the AHC Class 1 (AHC BIM-REVIT), which was based on the variables DBR1, DBR2, and DBR3. This observation can be interpreted as an indication that approximately $23 \%$ of the students regarded BIM as useful for technical engineering projects and for obtaining a high degree of assimilation after completing the 
course, felt that the tool used was simple to learn, and considered BIM useful for skill acquisition, especially for teamwork skills. Similar results were also found in other studies (20 Muriel, and Paloma, 2017; 19 Sacks and Barak, 2009).

The elements of the AHC-Opinion Classes 3-5-6 and AHC-BIMREVIT 5-6 are related (more than $40 \%$ of the sample in the AHC-Opinion Class 3 was contained in the AHC-BIMREVIT Class 5), which we can interpret as an indication that students who think that BIM is not very useful and does not help with skill acquisition consider the tool complex. This result has also been reported in other studies [20,51].

Regarding the 3D tool, more than $20 \%$ of the students considered BIM simple to use and useful for skill acquisition but felt that the 3D tool could be a barrier for the BIM implementation. These results are similar to those found in other studies in areas other than industrial engineering [50,52]. A direct relationship has been observed between the satisfaction with the use of BIM and the use of the tool. This result has also been found by other authors in professional, non-academic settings [63].

For this second phase, it was not possible to generate a linear regression model including the six factors extracted from the factor analysis, although it was possible to obtain a nonlinear model that explained the final student satisfaction ratings when all the factors were considered. If we compare the models, we can see that the nonlinear model better explains the variance in the system, with a somewhat lower MSE than the linear model. However, it is interesting to note that in the linear model, although there are low variance explanation rates, the coefficients have a statistically significant influence on the explanation of the model, which could allow the use of the linear model as a first approximation. The limitations of this study are directly related to the sample size. In addition, the variance rates explained by the factors were $94.91 \%$ and $91.26 \%$. This means that $5.09 \%$ and $8.74 \%$ of the information contained in the data were thrown away before the AHC analysis was even conducted. It is also interesting to note that the initial student training level in the fourth-year course for the degree in industrial technologies is not homogeneous due to the timing of the course and the year of implementation for the degree.

It is necessary to continue performing this evaluation in the coming academic courses to confirm the results obtained here and to test the validity of the proposed models. However, the present study does not incorporate uncertainty into the evaluations by evaluating student views, which may be a limitation of the results of this study.

Finally, it should be mentioned that during the current course, the resources available to the students are being expanded, and voluntary use of the DDS-CADC software package is an option for fourth-year students in the industrial technologies degree to use for their expert technical project course.

\section{Conclusions}

With the implementation of BIM in the engineering project course, it was intended to train future technical engineers in a way that allows them to see the possibilities of BIM and its limitations and problems and to have a vision of the multisectoral context in which projects are developed. Our findings can be summarized as follows:

More than $20 \%$ of the students regarded BIM as useful, and they rated their own level of BIM assimilation highly. They considered the 3D tool simple to use and BIM useful for skill acquisition.

A direct relationship was observed between the utility of BIM for developing the practice of the course and the view of BIM as useful for skill acquisition, especially for teamwork skills.

A direct relationship was observed between the satisfaction with the use of BIM and the use of the tool, but the 3D tool could be a barrier for the BIM implementation. This result has also been found by other authors in academic and professional, non-academic settings. It is important to emphasize that the teacher must stress that the 3D tool in itself is not BIM to focus the student's attention on the methodology and usefulness of building BIM models.

Given the results obtained here, the incorporation of BIM for voluntary use by students and the choice of the degree for which it has been proposed as a mandatory subject appear to be successful, 
and the results are encouraging. Phase 2 BIM could allow students to guarantee their start in postgraduate training in BIM and would provide better incorporation of BIM into professional engineering projects.

Author Contributions: Conceptualization, A.S., C.G.-G., P.Z. and Z.S.; Investigation, A.S., C.G.-G., P.Z. and Z.S.; Methodology, A.S., C.G.-G., P.Z. and Z.S.; Supervision, A.S., C.G.-G., P.Z. and Z.S.; Validation, A.S., C.G.-G., P.Z. and Z.S.; Writing-Original draft, A.S., C.G.-G., P.Z. and Z.S.; Writing-Review and editing, A.S., C.G.-G., P.Z. and Z.S.

Funding: This research received no external funding.

Acknowledgments: The authors would like to thank all the people who participated in this study.

Conflicts of Interest: The authors declare no conflict of interest.

\section{References}

1. Azhar, S.; Khalfan, M.; Maqsood, T. Building information modelling (BIM): Now and beyond. Constr. Econ. Build. 2015, 1212, 15-28. [CrossRef]

2. Leite, F. Project-based learning in a building information modeling for construction management course. J. Inf. Technol. Constr. (ITcon) 2016, 21, 164-176.

3. Wang, L.; Leite, F. Process-oriented approach of teaching building information modeling in construction management. J. Prof. Issues Eng. Educ. Pract. 2014, 140, 04014004. [CrossRef]

4. Czmoch, I.; Pẹkala, A. Traditional design versus BIM based design. Procedia Eng. 2014, 91, 210-215. [CrossRef]

5. Richards, M. Building Information Management: A Standard Framework and Guide to BS 1192; BSI Standards: London, UK, 2010; ISBN 978-0-580-70870-1.

6. Bozoglu, J. Collaboration and coordination learning modules for BIM education. J. Inf. Technol. Constr. (ITcon) 2016, 21, 152-163.

7. Wu, W.; Issa, R.R. BIM education and recruiting: Survey-based comparative analysis of issues, perceptions, and collaboration opportunities. J. Prof. Issues Eng. Educ. Pract. 2013, 140, 04013014. [CrossRef]

8. Abdirad, H. Metric-based BIM implementation assessment: A review of research and practice. Archit. Eng. Des. Manag. 2017, 13, 52-78. [CrossRef]

9. Solnosky, R.; Parfitt, M.K.; Holland, R.J. IPD and BIM-focused capstone course based on AEC industry needs and involvement. J. Prof. Issues Eng. Educ. Pract. 2013, 140, A4013001. [CrossRef]

10. Sampaio, A.Z. Proposal of Curricular Program to Introduce BIM in a Civil Engineering School. In Proceedings of the HELIX 2018 International Conference on Innovation, Engineering and Entrepreneurship, University of Minho, Guimaraes, Portugal, 27-29 June 2018. [CrossRef]

11. Hjelseth, E. Building Information Modeling (BIM) in Higher Education Based on Pedagogical Concepts and Standardised Methods. Int. J. 3-D Inf. Model. (IJ3DIM) 2017, 6, 35-50. [CrossRef]

12. Becerik-Gerber, A.M.A.B.; Kihong, K.; Farrokh, J. BIM-Enabled Virtual and Collaborative Construction Engineering and Management. J. Prof. Issues Eng. Educ. Pract. 2012, 138, 234-245. [CrossRef]

13. Joannides, M.M.; Olbina, S.; Issa, R.R. Implementation of building information modeling into accredited programs in architecture and construction education. Int. J. Constr. Educ. Res. 2012, 8, 83-100. [CrossRef]

14. Sacks, R.; Pikas, E. Building information modeling education for construction engineering and management. I: Industry requirements, state of the art, and gap analysis. J. Constr. Eng. Manag. 2013, 139, 04013016. [CrossRef]

15. Abdirad, H.; Dossick, C.S. BIM curriculum design in architecture, engineering, and construction education: A systematic review. J. Inf. Technol. Constr. (ITcon) 2016, 21, 250-271.

16. Adamu, Z.A.; Thorpe, T. How universities are teaching BIM: A review and case study from the UK. J. Inf. Technol. Constr. 2016, 21, 119-139.

17. de Frutos, D.G.; Vázquez, A.V.; de la Peña Esteban, F.D.; Zaldívar, O.L. Development of a methodology based on multidimensional learning in technical disciplines. Adv. Build. Educ. 2017, 1, 27-36. 
18. Leon, I.; Sagarna, M.; Mora, F.; Marieta, C.; Otaduy, J. El empleo de la tecnología BIM en la docencia vinculada a la Arquitectura: Aprendizaje cooperativo y colaborativo basado en Proyectos reales entre diferentes asignaturas. In Proceedings of the IV Jornadas sobre Innovación Docente en Arquitectura (JIDA'16), Escuela Técnica Superior de Arquitectura de Valencia, Universitat Politècnica de València, Valencia, Spain, 20-21 October 2016; pp. 191-197.

19. Nieto, E.; Rico, F.; Antón, D.; Moyano, J.J. BIM methodology in building engineering degree: Workshop in graphical expression of technologies subject. Build. Manag. 2017, 1, 37-47.

20. Lopez-Zaldivar, O.; Verdu-Vazquez, A.; Gil-Lopez, T.; Lozano-Diez, R.V. The Implementation of Building Information Modeling Technology in University Teaching: The Case of the Polytechnic University of Madrid. Int. J. Eng. Educ. 2017, 33, 712-722.

21. Caballero, M.B.; Pérez, P.Z.; Fernández-Coppel, I.A.; Lite, A.S. Implementation of BIM in the Subject Technical Industrial Projects-Degree in Industrial Technologies Engineering-University of Valladolid. In Project Management and Engineering Research; Springer: Cham, Switzerland, 2017; pp. 247-260.

22. Muriel, P.; Paloma, A. Implantación de la Tecnología BIM en la Asignatura Proyectos de los Grados de Ingenierías Industriales de la Universidad de Extremadura. Estudio de competencias genéricas. Ph.D Thesis, Universidad de Extremadura, Badajoz, Spain, 2017.

23. Plaza, E.M. Estrategias de implantación de enseñanza BIM en estudios de postgrado. Experiencia en la Universidad Politécnica de Madrid. Span. J. Build. Inf. Model. 2016, 1, 30-39.

24. Jurado, J.; Carrasco, O.L.; de Rueda, J.A. Implementation Framework for BIM Methodology in the Bachelor Degree of Architecture: A Case Study in a Spanish University. Int. J. 3-D Inf. Model. (IJ3DIM) 2017, 6, 1-18. [CrossRef]

25. ES BIM. Implantación de BIM en España. $4^{\text {a }}$ Reunión Comisión BIM. 2017. Available online: http: //www.esbim.es/ (accessed on 15 July 2019).

26. Sampaio, A.Z. BIM subject inserted in European technical schools. In Proceedings of the CINIE2019-3 ${ }^{\circ}$ Congreso Internacional de Innovación Educativa en Edificación, en la Escuela Técnica Superior de Edificación de la Universidad Politécnica de Madrid, Madrid, España, 6-8 March 2019; ISBN 978-84-16397-89-1.

27. Sampaio, A.Z. Introduction of BIM methodology in education: Concept and application. In Proceedings of the HEAd'18-4th International Conference on Higher Education Advances, Valencia, Spain, 20-22 June 2018.

28. Wu, W.; Kaushik, I. A BIM-based educational gaming prototype for undergraduate research and education in design for sustainable aging. In Winter Simulation Conference (WSC); IEEE: Piscataway, NJ, USA, 2015; pp. 1091-1102.

29. Palomera-Arias, R.; Liu, R. BIM laboratory exercises for a MEP systems course in a construction science and management program. J. Inf. Technol. Constr. (ITcon) 2016, 21, 188-203.

30. Mathews, M. BIM collaboration in student architectural technologist learning. J. Eng. Des. Technol. 2013, 11, 190-206.

31. Alreshidi, E.; Mourshed, M.; Rezgui, Y. Factors for effective BIM governance. J. Build. Eng. 2017, 10, 89-101. [CrossRef]

32. Elliott, J.W.; Glick, S.; Valdes-Vasquez, R. Student perceptions of model-based estimating. Int. J. Constr. Educ. Res. 2018, 15, 118-135. [CrossRef]

33. Ahn, Y.H.; Cho, C.S.; Lee, N. Building information modeling: Systematic course development for undergraduate construction students. J. Prof. Issues Eng. Educ. Pract. 2013, 139, 290-300. [CrossRef]

34. Chen, D.; Gehrig, G.B. Implementing Building Information Modeling in Construction Engineering Curricula. In Proceedings of the 2011 Annual Conference of the American Society Engineering Education, Vancouver, BC, Canada, 26-29 June 2011.

35. Lee, N.; Hollar, D.A. Probing BIM education in construction engineering and management programs using industry perceptions. In Proceedings of the 49th ASC Annual Information Conference Proceedings, California Polytechnic State University, San Luis Obispo, CA, USA, 10-13 April 2013; pp. 467-476.

36. Jung, Y.; Joo, M. Building information modelling (BIM) framework for practical implementation. Autom. Constr. 2011, 20, 126-133. [CrossRef]

37. Puolitaival, T.; Forsythe, P. Practical challenges of BIM education. Struct. Surv. 2016, 34, 351-366. [CrossRef] 
38. Underwood, J.; Ayoade, O.; Khosrowshahi, F.; Greenwood, D.; Pittard, S.; Garvey, R. Current Position and Associated Challenges of BIM Education in UK Higher Education; BIM Academic Forum: Heslington York, UK, 2015.

39. Panuwatwanich, K.; Wong, M.L.; Doh, J.H.; Stewart, R.A.; McCarthy, T.J. Integrating building information modelling (BIM) into Engineering education: An exploratory study of industry perceptions using social network data. In Proceedings of the 2013 Australasian Association for Engineering Education Conference (AAEE2013), Gold Coast, Australia, 8-11 December 2013.

40. Hon, C.K.; Utiome, E.; Drogemuller, R.; Owen, R.; Beazley, S.; Nepal, M.; Coffey, V. An evaluation of learning and teaching initiatives for BIM education at Queensland University of Technology (QUT). In Proceedings of the CIB W78 Conference, Queensland University of Technology, Brisbane, Australia, 31 October-2 November 2016.

41. Nielsen, D.; Fleming, M.; Kumarasuriyar, A.C. An innovative learning model for teaching architectural technology using building information modelling: A Queensland University of Technology perspective. In Proceedings of the EDULearn09 International Conference on Education and New Learning Technologies, Barcelona, Spain, 6-8 July 2009.

42. Suwal, S.; Singh, V. Assessing students' sentiments towards the use of a Building Information Modelling (BIM) learning platform in a construction project management course. Eur. J. Eng. Educ. 2018, 43, 492-506. [CrossRef]

43. Zou, P.X.W.; Xu, X.; Jin, R.; Painting, N.; Li, B. Investigation of AEC Students' Perceptions towards BIM Practice-a Case Study of Swinburne University of Technology. J. Prof. Issues Eng. 2019, 14. [CrossRef]

44. Jin, R.; Yang, T.; Piroozfar, P.; Kang, B.G.; Wanatowski, D.; Hancock, C.M.; Tang, L. Project-based pedagogy in interdisciplinary building design adopting BIM. Eng. Constr. Archit. Manag. 2018, 25, 1376-1397. [CrossRef]

45. Blanco, M.; Gonzalez, C.; Sanchez-Lite, A.; Sebastian, M.A. A Practical Evaluation of a Collaborative Learning Method for Engineering Project Subjects. IEEE Access 2017, 5, 19363-19372. [CrossRef]

46. Succar, B.; Sher, W.; Williams, A. Measuring BIM performance: Five metrics. Archit. Eng. Des. Manag. 2012, 8, 120-142. [CrossRef]

47. Succar, B.; Sher, W.; Williams, A. An integrated approach to BIM competency assessment, acquisition and application. Autom. Constr. 2013, 35, 174-189. [CrossRef]

48. Blanco, M.; Sanchez-Lite, A.; Garcia, M. Learning system for engineering projects. In Proceedings of the 19th International Congress on Project Management and Engineering, Granada, Spain, 15-17 July 2015; pp. 2351-2362.

49. Ozcan-Deniz, G. The AEC students' perspective in the learning process of CAD and BIM. In Proceedings of the 10th BIM Academic Symposium \& Job Task Analysis Review, Orlando, FL, USA, 4-5 April 2016.

50. Rosli, M.F.; Razak, A.S.A.; Younus, M.A. To BIM or not to BIM: A pilot study on University of Malaya's architectural students' software preference. J. Des. Built Environ. 2016, 16, 13-26. [CrossRef]

51. Watson, A. Digital buildings-Challenges and opportunities. Adv. Eng. Inform. 2011, 25, 573-581. [CrossRef]

52. Sacks, R.; Barak, R. Teaching building information modeling as an integral part of freshman year civil engineering education. J. Prof. Issues Eng. Educ. Pract. 2009, 136, 30-38. [CrossRef]

53. López Soblechero, M.V.; González Gaya, C.; Hernández Ramírez, J.J. A Comparative Study of Classroom and Online Distance Modes of Official Vocational Education and Training. PLoS ONE 2014, 9, e96052. [CrossRef]

54. Gorsuch, R.L. Factor Analysis; Lawrence Erlbaum Associates: Hillsdale, NJ, USA, 1983.

55. Kaiser, H.F. The varimax criterion for analytic rotation in factor analysis. Psychometrika 1958, 23, $187-200$. [CrossRef]

56. Holgado-Tello, F.P.; Chacón-Moscoso, S.; Barbero-García, I.; Vila-Abad, E. Polychoric versus Pearson correlations in exploratory and confirmatory factor analysis of ordinal variables. Qual. Quant. 2010, 44, 153. [CrossRef]

57. Beavers, A.S.; Lounsbury, J.W.; Richards, J.K.; Huck, S.W.; Skolits, G.J.; Esquivel, S.L. Practical considerations for using exploratory factor analysis in educational research. Pract. Assess. Res. Eval. 2013, 18, 1-13.

58. Biernacki, C.; Celeux, G.; Govaert, G. Assessing a mixture model for clustering with the integrated completed likelihood. IEEE Trans. Pattern Anal. Mach. Intell. 2000, 22, 719-725. [CrossRef]

59. Nemenyi, P. Distribution-Free Multiple Comparisons. Ph.D. Thesis, University Microfilms, Princeton University, Ann Arbor, MI, USA, 1963; pp. 264-278. 
60. Zhu, S.B.; Li, Z.L.; Zhang, S.M.; Liang, L.L.; Zhang, H.F. Natural gas pipeline valve leakage rate estimation via factor and cluster analysis of acoustic emissions. Measurement 2018, 125, 48-55. [CrossRef]

61. Mahalanobis, P.C. On the generalized distance in statistics. Natl. Inst. Sci. India 1936, 2, 49-55.

62. Friedman, M. The use of ranks to avoid the assumption of normality implicit in the analysis of variance. J. Am. Stat. Assoc. 1937, 32, 675-701. [CrossRef]

63. Wang, G.; Song, J. The relation of perceived benefits and organizational supports to user satisfaction with building information model (BIM). Comput. Hum. Behav. 2017, 68, 493-500. [CrossRef]

(C) 2019 by the authors. Licensee MDPI, Basel, Switzerland. This article is an open access article distributed under the terms and conditions of the Creative Commons Attribution (CC BY) license (http://creativecommons.org/licenses/by/4.0/). 